\title{
Gambaran Kejadian Fraktur Femur di RSUP Dr. M. Djamil Padang Tahun 2016- 2018
}

\author{
Nur Sadia Suhail Ahmad ${ }^{1}$, Rizki Rahmadian ${ }^{2}$, Dwi Yulia ${ }^{3}$ \\ ${ }^{1}$ Profesi Dokter FK UNAND (Fakultas Kedokteran Universitas Andalas Padang) \\ ${ }^{2}$ Bagian IImu Bedah FK UNAND/RSUP Dr. M. Djamil Padang \\ ${ }^{3}$ Bagian Patologi Klinik FK UNAND/RSUP Dr. M. Djamil Padang
}

\section{A B S T R A C T}

\begin{abstract}
Latar Belakang: Fraktur adalah kondisi terjadinya diskontinuitas tulang dan atau tulang rawan dan merupakan kasus fraktur terbanyak terjadi pada ekstremitas bawah. Fraktur femur pada usia muda biasanya disebabkan cedera traumatik seperti kecelakaan lalulintas dan pada usia tua disebabkan oleh kondisi patologis.

Objektif: Mengetahui gambaran kejadian fraktur femur di RSUP Dr. M. Djamil Padang pada tahun 2016-2018.

Metode: Penelitian ini merupakan penelitian deskriptif dan teknik pengambilan sampel pada penelitian ini adalah total sampling dengan mengambil 256 data dari rekam medis pasien dengan diagnosis fraktur femur sebagai diagnosis primer atau sekunder. Penelitian ini dilakukan di bagian rekam medik RSUP Dr. M. Djamil Padang pada tahun 2016-2018.

Hasil: Penelitian ini mendapatkan bahwa jenis kelamin laki-laki lebih sering mengalami fraktur femur $(62,9 \%)$. Lokasi fraktur tersering terjadi adalah pada bagian medial shaft $(34,0 \%)$. Kelompok usia terbanyak mengalami fraktur adalah $\geq 60$ tahun $(28,1 \%)$. Fraktur tertutup lebih sering terjadi $(86,3 \%)$ dan cedera traumatik merupakan faktor tersering fraktur $(72,7 \%)$. Penatalaksanaan fraktur yang paling sering dilakukan adalah operatif (72.3\%).

Simpulan: Fraktur tertutup banyak terjadi dengan jenis kelamin terbanyak adalah laki-laki, paling sering mengenai usia $\geq 60$ tahun dengan lokasi fraktur tersering pada medial shaft. Cedera traumatik adalah faktor tersering dan penatalaksanaan operatif banyak dilakukan.
\end{abstract}

Kata kunci: cedera traumatik, fraktur femur, kondisi patologis

Background: Fractures are conditions of bone and / or cartilage continuation and are the most common cases of fractures in the lower extremities. Femoral fractures at a young age are usually caused by traumatic injuries such as traffic accidents and in old age due to pathological conditions.

Objective: To determine the description of the occurrence of femoral fractures in RSUP Dr. M. Djamil Padang in 2016-2018.

Methods: This research was a descriptive study and the sampling technique in this study is total sampling by taking 256 data from the medical records of patients with a diagnosis of femoral fracture as a primary or secondary diagnosis. This research was conducted in the medical record section of
RSUP Dr.M. Djamil Padang in 2016-2018.

Results: Male gender more often experienced femoral fractures (62.9\%). The location of the most common fracture was in the medial shaft (34.0\%). The age group with the most fractures was $\geq 60$ years (28.1\%). Closed fractures are more common (86.3\%) and traumatic injuries are the most common fracture factor (72.7\%). The most common fracture management is operative (72.3\%).

Conclusion: Closed fractures occur mostly with the most sex being male, most often regarding age $\geq 60$ years with the location of the most common fracture on the medial shaft. Traumatic injury is the most common factor and many operative management is performed.

Keyword: femur fracture, traumatic injury, pathological condition

\section{Apa yang sudah diketahui tentang topik ini?}

Fraktur femur terjadi dikarekan cedera traumatik dan kondisi patologis.

\section{Apa yang ditambahkan pada studi ini?}

Fraktur femur pada usia muda biasanya dapat ditatalaksana dengan lebih mudah dan proses penyembuhan lebih cepat.

\section{CORRESPONDING AUTHOR}

Phone: +6281266057325

E-mail:wi.yulia25@yahoo.com

\section{ARTICLE INFORMATION}

Received: July $29^{\text {th }}, 2020$

Revised: April $4^{\text {th }}, 2021$

Available online: May $27^{\text {th }}, 2021$ 


\section{Pendahuluan}

Fraktur adalah kondisi terjadinya diskontinuitas tulang dan atau tulang rawan, yang bersifat total atau sebagian yang disebabkan oleh trauma atau tenaga fisik. Kegagalan tulang dalam menahan tekanan, membengkok, memutar dan tarikan dapat menyebabkan terjadinya fraktur atau patah tulang. Tulang femur merupakan salah satu tulang yang terpanjang, terbesar, terkuat dan terberat pada badan manusia dan merupakan tulang penahan beban utama yang terletak di ekstremitas bawah.1,2,3

Menurut penelitian yang dilakukan di Pakistan oleh Adnan RM, insiden kasus fraktur femur di Pakistan meningkat dari tahun ke tahun dikarenakan meningkatnya kasus kecelakaan kendaraan seiring dengan meningkatnya beban lalu lintas yang padat. Didapatkan pasien dengan usia yang lebih muda, yaitu usia $<40$ tahun sering mengalami kasus fraktur femur karena kecelakaan. Insiden fraktur femur pada wanita adalah fraktur terbanyak kedua dengan prevalensi 17 per 10.000 orang per tahun dan nomor tujuh terbanyak pada pria dengan prevalensi 5,3 per orang per tahun. Puncak distribusi usia pada fraktur femur adalah pada usia dewasa $15-34$ tahun dan orang tua diatas 70 tahun. Fraktur femur yang disebabkan oleh energi yang lemah atau rendah kebanyakkan ditemukan pada pasien yang memiliki riwayat penyakit kronik atau memiliki kondisi osteopenia pada femur. 4,5

Sebuah penelitian yang dilakukan di Cina oleh Chinese National Fracture Survey (CNFS) memperoleh data, lebih dari $80 \%$ kasus fraktur terjadi di rumah dan di jalan disebabkan cedera low-energy. Fraktur yang berhubungan dengan osteoporosis diestimasikan terjadi sebanyak 70\% pada pasien usia lanjut. Dalam setahun, diperkirakan sebanyak 1,4 miliyar individu yang berusia pertengahan dan juga usia lanjut, mendapatkan fraktur ekstremitas yang disebabkan oleh cedera low-energy. Angka kejadian tersebut diprediksi akan terus meningkat secara dramatis dalam 10 tahun mendatang dan hal ini menjadi suatu tantangan besar dari segi biaya perawatan medis bagi lembaga atau badan pembuat kebijakan kesehatan Cina.6,7

Faktor penyebab terjadinya fraktur adalah cedera traumatik dan patologis. Osteoporosis dikatakan sebagai penyakit wanita, karena secara garis besar lebih banyak terjadi pada wanita https://doi.org/10.25077/jikesi.v1i3.82 dibandingkan pada pria. ${ }^{8}$ Pada penelitian yang dilakukan di Jepang berdasarkan The National Database of Health Insurance Claims and Specific Health Checkups of Japan, kasus fraktur yang disebabkan oleh kerapuhan tulang seperti osteoporosis, didapatkan sebanyak $17.7 \%$ kasus terjadi pada tulang femur proksimal. Pada pria didapatkan sebanyak 15.402 kasus atau $17.8 \%$ dan pada wanita didapatkan sebanyak 70.937 kasus atau 82.2\%. ${ }^{9}$ Sedangkan untuk kasus fraktur akibat cedera traumatik seperti kecelakaan didapatkan lebih banyak terjadi pada pria dibandingkan pada wanita. ${ }^{10}$ Hal ini sejalan dengan penelitian yang dilakukan oleh The National Osteoporosis Foundation (NOF), didapatkan bahwa 9.1 miliar kasus osteoporosis terjadi pada wanita dan penambahan pada kasus massa tulang yang rendah sebanyak 26 milliar. Sedangkan pada pria didapatkan 2.8 miliar kasus osteoporosis dan penambahan kasus massa tulang rendah sebanyak 14.4 miliar. $^{8}$

Fraktur ekstremitas bawah termasuk kedalam 10 fraktur yang paling sering terjadi pada kasus kecelakaan kenderaan bermotor dimana dari 147.348 kasus fraktur pada ekstremitas bawah, $60 \%$ kasus terjadi pada pria dan $40 \%$ kasus terjadi pada wanita dan dari 63.826 kasus fraktur terbuka pada ekstremitas bawah, $60.13 \%$ kasus terjadi pada pria dan $39.87 \%$ kasus terjadi pada wanita. ${ }^{10}$ Insidensi fraktur juga meningkat di Amerika yang disebabkan oleh faktor urbanisasi dan trauma. Di Amerika, terjadi kasus fraktur sebanyak 6 miliyar setiap tahunnya, dan diestimasikan bahwa populasi Amerika memiliki resiko sebanyak $40 \%$ untuk mengalami fraktur seumur hidup. ${ }^{11}$ Fraktur stress terjadi pada kebanyakan atlet dengan 80-95 \% kasus melibatkan ekstremitas bawah. ${ }^{13}$

Menurut hasil satu penelitian yang dilakukan di Indonesia, pasien dengan fraktur femur sebanyak $36 \%$ merupakan pasien yang paling sering konsul ke poli ortopaedi Rumah Sakit Umum Daerah Dr. Soetomo Surabaya pada tahun 2013-2016. Penyebab utama dari kasus fraktur adalah kecelakaan lalu lintas sebesar 92\% dan kebanyakannya adalah kasus fraktur tertutup dengan prevalensi $71 \% .{ }^{1}$ Fraktur femur dikatakan paling sering terjadi pada laki-laki di bawah usia 30 tahun. Penyebab tersering fraktur pada lakilaki adalah kecelakaan motor dan pada wanita karena terjatuh. Kasus fraktur femur merupakan 
kasus yang paling sering terjadi yaitu sebesar $39 \%$ diikuti fraktur humerus 15\%, fraktur tibia dan fibula $11 \%$, dimana penyebab terbesar fraktur femur adalah kecelakaan lalu lintas yang biasanya disebabkan oleh kecelakaan mobil, motor, atau kendaraan rekreasi sebesar $62,6 \%$ dan jatuh dari ketinggian 37,3\%. Fraktur juga merupakan kasus kedua terbanyak yang terjadi pada jemaah haji Indonesia yang dipengaruhi oleh beberapa faktor seperti kelelahan, usia dan osteoporosis. ${ }^{4,14}$

Sampai saat ini, di Indonesia, data epidemiologi yang terbaru mengenai kasus patah tulang femur masih sangat sedikit terutama di Sumatera Barat. Data tersebut sangat penting dalam mengetahui seberapa besar gambaran patah tulang femur yang terjadi di Indonesia. ${ }^{4}$ Penanganan yang dapat dilakukan pada pasien fraktur adalah tindakan konservatif dan pembedahan. Pembedahan yang dilakukan meliputi fiksasi interna dan fiksasi eksterna. ${ }^{13}$

Berdasarkan latar belakang di atas, penulis terdorong untuk melakukan penelitian ini untuk mengetahui gambaran kejadian fraktur femur di RSUP Dr. M. Djamil, Padang pada tahun 20162018, maka penelitian ini penting untuk dilakukan karena merupakan Rumah sakit rujukan utama di Sumatera Barat.

\section{Metode}

Jenis penelitian ini adalah penelitian deskriptif. Penelitian dilakukan dari bulan Januari-Maret 2020 di Bagian Rekam Medis RSUP Dr. M. Djamil Padang, Sumatera Barat, Indonesia.

Populasi penelitian ini adalah semua pasien dengan diagnosis fraktur femur yang dirawat di RSUP Dr. M. Djamil Padang pada tahun 2016-2018 dan memenuhi kriteria inklusi. Kriteria inklusi yaitu semua pasien fraktur femur sebagai diagnosis utama atau sekunder. Kriteria eksklusi adalah pasien dengan data rekam medis tidak lengkap. Teknik pengambilan sampel adalah dengan total sampling. Data yang diambil pada penelitian ini adalah data sekunder.

Data yang memenuhi kriteria inklusi dan data yang dibutuhkan untuk penelitian ini akan dicatat secara manual. Langkah-langkah pengolahan data yang dilakukan adalah editting yaitu data yang didapatkan diperiksa kejelasan dan kelengkapannya terlebih dahulu sebelum diproses, coding yaitu proses pemberian kode kepada setiap data variable yang telah terkumpul yang berfungsi untuk memudahkan proses pengolahan data, entry yaitu memasukkan data ke dalam program komputer ${ }_{2}$ dan cleaning yaitu data yang telah dimasukkan diperiksa kembali dengan tujuan memastikan bahwa data tersebut telah bersih dari kesalahan, baik dalam pengkodean ataupun kesalahan membaca kode.

Analisis data dilakukan dengan analisis univariat, yaitu analisis yang menggambarkan distribusi frekuensi dari masing-masing variabel yang diteliti yaitu distribusi fraktur femur berdasarkan jenis kelamin, usia, lokasi fraktur, jenis fraktur, faktor penyebab dan penatalaksanaan fraktur pada pasien yang dirawat di RSUP Dr. M. Djamil Padang tahun 20162018. Penelitian ini telah lulus kaji etik dengan nomor surat: 15/KEPK/2020 yang telah dikeluarkan oleh Komite Etik Penelitian Kesehatan RSUP Dr. M. Djamil Padang.

\section{Hasil}

Penelitian ini telah dilakukan di RSUP Dr. M. Djamil Padang dengan 256 sampel memenuhi kriteria inklusi.

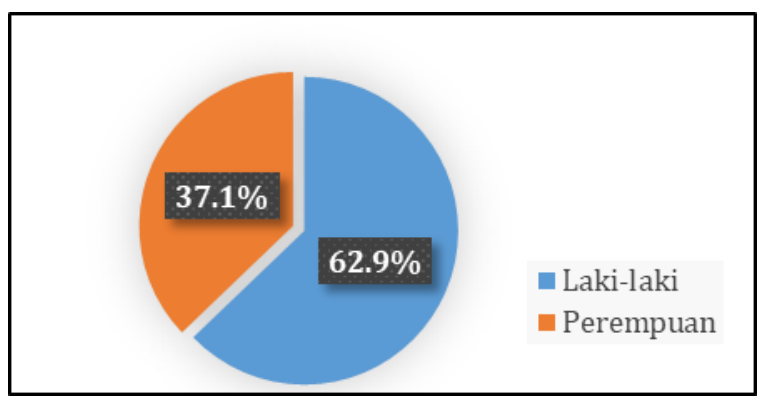

Gambar 1 Distribusi frekuensi sampel penelitian berdasarkan jenis kelamin

Berdasarkan gambar 1 terlihat bahwa kasus fraktur femur di RSUP Dr. M. Djamil Padang pada tahun 2016-2018, lebih dari separuh sampel yang dianalisis terjadi pada pasien laki -laki sebanyak 161 orang (62.9\%).

Tabel 1 Distribusi frekuensi sampel penelitian berdasarkan usia

\begin{tabular}{ccc}
\hline Usia & frekuensi & $\%$ \\
\hline$\leq 5$ tahun & 7 & 2.7 \\
6-18 tahun & 67 & 26.2 \\
19-39 tahun & 54 & 21.1 \\
40-59 tahun & 56 & 21.9 \\
$\geq 60$ tahun & 72 & 28.1 \\
\hline Total & 256 & 100.0
\end{tabular}


Berdasarkan tabel 1, kasus fraktur femur paling banyak terjadi pada golongan usia $\geq 60$ tahun yang berjumlah 72 orang $(28.1 \%)$. Kasus fraktur femur paling jarang terjadi pada usia $\leq 5$ tahun berjumlah 7 orang $(2.7 \%)$.

Tabel 2 Distribusi frekuensi sampel penelitian berdasarkan lokasi fraktur

\begin{tabular}{ccc}
\hline Lokasi fraktur & frekuensi & $\%$ \\
\hline Caput & 6 & 2.3 \\
Collum & 45 & 17.6 \\
Intertrokanter & 45 & 17.6 \\
Subtrokanter & 7 & 2.7 \\
Proksimal shaft & 24 & 9.4 \\
Medial shaft & 87 & 34.0 \\
Distal shaft & 27 & 10.5 \\
Suprakondilar & 8 & 3.1 \\
Interkondilar & 7 & 2.7 \\
\hline Total & 256 & 100.0
\end{tabular}

Berdasarkan tabel 2 dapat dilihat lokasi paling sering terjadi fraktur femur adalah di proksimal femur pada collum dan intertrokanter masingmasing 45 kasus (17.6\%), pada bagian shaft paling banyak di medial shaft 87 kasus (34\%) dan pada distal femur paling banyak pada suprakondilar 8 kasus (3.1\%).

Tabel 3 Distribusi frekuensi sampel penelitian berdasarkan jenis fraktur dan faktor penyebab fraktur

\begin{tabular}{ccc}
\hline Jenis fraktur & frekuensi & $\%$ \\
\hline Terbuka & 35 & 13.7 \\
Tertutup & 221 & 86.3 \\
\hline Total & 256 & 100.0 \\
\hline Faktor penyebab fraktur & & \\
\hline Traumatik & 186 & 72.7 \\
Patologis & 70 & 27.3 \\
\hline Total & 256 & 100.0
\end{tabular}

Berdasarkan tabel 3 didapatkan fraktur terbuka terjadi yaitu sebanyak 35 kasus (13.7\%) dan fraktur tertutup sebanyak 221 kasus (86.3\%). Faktor penyebab fraktur didapatkan paling banyak disebabkan oleh traumatik yakni 186 kasus (72.7\%).

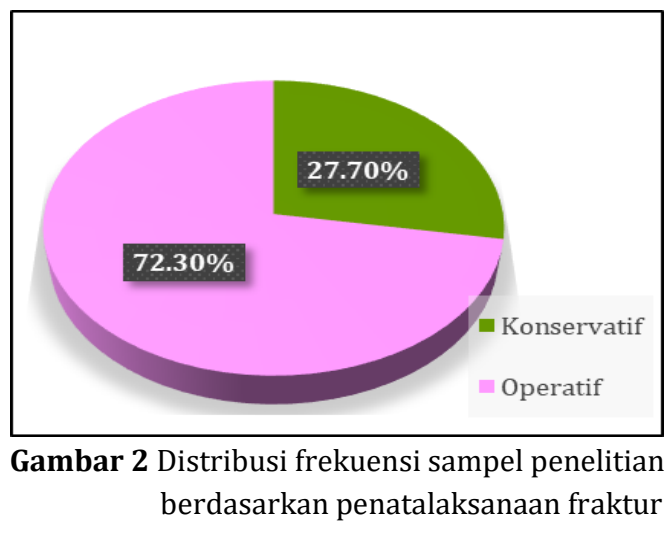

Berdasarkan gambar 2 tatalaksana yang paling banyak dilakukan adalah tatalaksana yang bersifat operatif yaitu sebanyak 185 kasus (72.3\%) dan tatalaksana konservatif pada 71 kasus $(27.7 \%)$.

\section{Pembahasan}

Berdasarkan dari data yang diperoleh dari penelitian ini, didapatkan jenis kelamin paling banyak terdapat pada laki-laki yaitu sebanyak 161 orang (62.9\%) dan jenis kelamin perempuan didapatkan sebanyak 95 orang (37.1\%). Hal ini sejalan dengan penelitian yang dilakukan di Tanzania dimana kasus fraktur femur lebih banyak terjadi pada laki-laki yaitu sebanyak 138 kasus dari 210 kasus yang terjadi, hal ini berkaitan dengan tingginya angka kejadian kecelakaan lalu lintas. ${ }^{14}$ Laki-laki lebih banyak mengalami kecelakaan lalu lintas dapat dipicu oleh kecenderungan laki-laki dalam berkendara dimana laki-laki lebih sering mengendarai kendaraan dengan kecepatan dan juga laki-laki lebih sering terekspos di jalan raya dibandingkan perempuan. ${ }^{15}$ Penelitian yang dilakukan di Indonesia pada 2019 mendapatkan, kasus fraktur ekstremitas bawah lebih sering terjadi pada lakilaki berbanding pada wanita. Dimana 73\% kasus didapatkan terjadi pada laki-laki dan hanya $23 \%$ kasus terjadi pada wanita. ${ }^{16}$

Pada penelitian ini secara umum didapatkan kasus fraktur femur paling sering terjadi pada golongan usia $\geq 60$ tahun yang berjumlah 72 orang $(28.1 \%)$ dan paling jarang terjadi pada usia $\leq 5$ tahun berjumlah 7 orang $(2.7 \%)$. Hal ini dikarenakan, RSUP Dr. M. Djamil Padang merupakan rumah sakit rujukan tersier, RS tipe $\mathrm{A}$ bagi kasus yang tidak dapat ditatalaksana di rumah sakit rujukan terutamanya kasus pada golongan usia tua disebabkan lebih banyak komplikasi. Kebiasaanya, kasus fraktur pada 
pasien usia muda sudah ditatalaksanaan di rumah sakit daerah. Pada sebuah penelitian yang dilakukan di Pakistan pada tahun 2012, dimana dari 1756 kasus yang diteliti, 897 kasus (51.1\%) merupakan pasien berusia dibawah 40 tahun dan 859 kasus (48.9\%) merupakan pasien berusia diatas 40 tahun. ${ }^{5}$ Penelitian yang dilakukan di RSUD Dr H Chasan Boesoirie Ternate pada tahun 2018 mendapatkan kasus fraktur ekstremitas bawah lebih dominan terjadi pada usia $>18$ tahun (68.6\%) dan pada usia < 18 tahun hanya $31.4 \%$ kasus. Hal ini disebabkan oleh kecederaan traumatik terutamanya kecelakaan lalulintas. ${ }^{17}$

Hasil penelitian ini didapatkan lokasi paling sering terjadi fraktur femur adalah di proksimal femur pada collum dan intertrokanter masingmasing 45 kasus (17.6\%), pada bagian shaft paling banyak di medial shaft 87 kasus (34\%) dan pada distal femur paling banyak pada suprakondilar 8 kasus (3.1\%). Hal ini sejalan dengan penelitian yang dilakukan di Cina pada 2018 lokasi fraktur pada bagian proksimal tulang femur yang paling sering terjadi pada bagian collum 997 kasus (36.1\%), diikuti bagian trokanter sebanyak 960 kasus (34.8\%) dan bagian caput 42 kasus $(1.5 \%){ }^{18}$ Hal ini dikarenakan, pada bagian proksimal femur, collum merupakan bagian yang rentan mengalami osteoporosis dan apabila seseorang jatuh walau dengan kekuatan yang kecil ataupun energi yang rendah dapat menyebabkan fraktur. ${ }^{6}$

Untuk hasil pada bagian shaft didukung oleh sebuah penelitian yang dilakukan di Arab Saudi, dengan lokasi terbanyak terjadi fraktur adalah bagian medial shaft dengan persentase sebesar $64 \%$ dari jumlah kasus fraktur femur. ${ }^{19}$ Sedangkan untuk bagian distal femur sejalan dengan penelitian yang dilakukan di Denmark pada 2018, fraktur yang terjadi pada bagian distal tulang femur adalah sangat jarang dengan hanya prevalensi sebesar $0.5 \%$ dari keseluruhan lokasi lain fraktur terjadi pada tulang femur. ${ }^{20}$

Jenis fraktur femur yang paling sering terjadi dari hasil penelitian ini adalah jenis tertutup dengan prevalensi sebesar 221 kasus (86.3\%) dan fraktur dengan jenis terbuka 35 kasus (13.7\%) yang terjadi. Fraktur terbuka biasanya terjadi pada kasus high-energy trauma yaitu kekuatan energy trauma lebih besar dari ketahanan tulang. Pada penelitian yang di lakukan di RSUP Sanglah Denpasar pada 2013, mendapatkan pasien dengan fraktur femur tertutup akibat kecelakaan lalu lintas terjadi sebanyak 85 kasus (72.6\%) dan fraktur terbuka hanya 32 kasus (27.4\%). ${ }^{4}$ Kasus fraktur terbuka dikatakan jarang terjadi. Penelitian yang dilakukan oleh The Royal Infirmary of Edinburgh, United Kingdom mendapatkan dari bulan Januari 1988 hingga September 2008, terdapat 2071 kasus fraktur femur yang dirawat, dimana hanya 153 kasus $(7,4 \%)$ yang mengalami kasus fraktur terbuka. ${ }^{21}$ Penentuan jenis fraktur yang terjadi tergantung kepada kekuatan, magnitud, dan kondisi tulang yaitu bone density dan kandungan mineral. Apabila kekuatan trauma melebihi kemampuan tulang untuk menahan kekuatan maka dapat menyebabkan terjadinya fraktur terbuka. ${ }^{3}$

Hasil penelitian ini didapatkan cedera traumatik merupakan faktor penyebab tersering terjadinya kasus fraktur di RSUP Dr. M. Djamil Padang pada tahun 2016-2018 yakni sebesar 186 kasus $(72.7 \%)$. Hal ini sejalan dengan penelitian yang dilakukan di Cameroon pada 2019, yang mendapatkan prevalensi terjadinya cedera pada ekstremitas bawah akibat kecelakaan lalu lintas adalah sebesar 47.93\%. Hal ini dikarenakan ekstremitas bawah merupakan salah satu dari bagian badan yang paling sering terekspos pada kasus kecelakaan lalu lintas. ${ }^{22}$

Berdasarkan hasil penelitian ini didapatkan penatalaksanaan yang paling sering dilakukan adalah yang bersifat operatif yaitu sebanyak 185 kasus $(72.3 \%)$ dan hanya 71 kasus $(27.7 \%)$ yang bersifat konservatif. Terapi operatif dipilih karena lebih bersifat definitif dalam menyembuhkan fraktur. Tambahan pula, mayoritas kasus fraktur yang dirawat di RSUP Dr. M. Djamil Padang adalah kasus rujukan yang memerlukan terapi yang lebih adekuat. Terapi konservatif seperti traksi dikatakan tidak terlihat membantu dalam mengurangkan nyeri serta dapat menyebabkan terjadinya komplikasi seperti nekrosis pada kulit dan meningkatkan kemungkinan terjadinya deep veen thrombosis. Pemilihan implan tergantung kepada usia pasien, kemungkinan penyakit komorbid yang dimiliki pasien dan bentuk fraktur yang terjadi. ${ }^{23}$

\section{Simpulan}

Berdasarkan penelitian yang telah dilakukan tentang fraktur femur pada pasien yang dirawat di RSUP Dr. M. Djamil Padang pada tahun 2016- 
2018, didapatkan kesimpulan bahwa jenis kelamin yang paling banyak mengalami fraktur femur adalah laki-laki. Usia pasien fraktur femur terbanyak adalah $\geq 60$ tahun. Lokasi fraktur paling banyak terjadi pada bagian medial. Jenis fraktur femur yang paling sering terjadi adalah fraktur tertutup. Faktor penyebab fraktur femur terbanyak adalah cedera traumatik. Penatalaksanaan fraktur femur yang paling banyak dilakukan adalah tindakan operatif.

\section{Ucapan Terima Kasih}

Terima kasih penulis sampaikan kepada semua instansi yang telah membantu dalam menyelesaian penelitian ini terutama bagian rekam medik RSUP Dr. M. Djamil Padang dan Fakultas Kedokteran Universitas Andalas.

\section{Daftar Pustaka}

1. Noorisa R, Apriliwati D, Aziz A, Bayusentono S. The characteristics of patients with femoral fracture in Department of Orthopaedic and Traumatology RSUD Dr. Soetomo Surabaya 2013-2016. Journal of Orthopaedic \& Traumatology Surabaya. 2017;6(1):111.

2. Rasjad PC. Pengantar ilmu bedah ortopedi. 2nd ed. Penerbit Lamumpatue, Makasssar; 2003.

3. Salminen S. Femoral shaft fractures in adults: epidemiology, fracture patterns, nonunions, and fatigue fractures [dissertation]. Helsinki: University of Helsinki; 2005.

4. Desiartama A, Arayana IGNW. Gambaran karakteristik pasien fraktur femur akibat kecelakaan lalu lintas pada orang dewasa di Rumah Sakit Umum Pusat Sanglah Denpasar tahun 2013. E-jurnal Medika. Mei 2017;6(5).

5. Adnan RM, Zia MI, Amin J, Khan R, Ahmed S, Danish KF. Frequency of femoral fractures; Comparison in patients less than and more than 40 years of age. Professional Med J. 2012;19(1): 011-014.

6. Zhu B, Liu S, Chen W, Liu B, Zhang F, Lv H, dkk. Epidemiology of low-energy lower extremity fractures in Chinese populations aged 50 years and above Jan 2019

7. Chen W, Lv H, Liu S, Liu B, Zhu Y, Chen X, dkk. National incidence of traumatic fractures in China: a retrospective survey of 512187 individuals. 2017;5:807-817.

8. Cawthon PM. Gender differences in osteoporosis and fractures. July 2011;469(7):1900-1905.

9. Ihara N, Ohara E, Bando Y, Yoshida T, Ohara M, Kirino Y. Fragility fractures in older people in Japan based on the National Health Insurance Claims database. 2019;42(5):778-785.

10. Pan RH, Chang NT, Chu D, Hsu KF, Hsu YN, Hsu Jc, et al. Epidemiology of orthopedic fractures and other injuries among inpatients admitted due to traffic accidents : A 10-year nationwide survey in Taiwan. 2014;637872:7.

11. Corarrino J. Fracture repairs: mechanism and management. 2015;11(10):960-967
12. Abbott A, Bird ML, Wild E, Brown SM, Stewart G, Mulcahey MK. Part I : epidemiology and risk factors for stress fractures in female athletes. July 2019;11:1-8

13. Awori N, Cairns J, Hankins G, Hiazdi JW, James JH, Nundy S, dkk. Buku bedah primer: trauma. Penerbit EGC; 2002.

14. Hollis AC, Ebbs RB, Mandari FN. The epidemiology and treatment of femur fractures at northern Tanzanian referral centre. 2015;22:338.

15. Singh R, Singh HK, Gupta SC, Kumar Y. Pattern, severity, and circumtances of injuries substained in road traffic accidents: A tertiary care- hospital based study. Jan-Mar 2014; 39(1):30-34.

16. Ramadhani RP, Romadhona N, Djojosugito MA, Dyana EH, Rukanta D. Hubungan jenis kecelakaan dengan tipe fraktur pada fraktur tulang panjang ekstremitas bawah. 2019;1(1):32-35.

17. Ridwan UN, Pattiiha AM, Selomo PAM. Karakteristik kasus fraktur ekstremitas bawah di Rumah Sakit Umum Daerah Dr H Chasan Boesoirie Ternate pada tahun 2018. 2019;1(1):9-15.

18. Chang MW, Liu HT, Huang CY, Chien PC, Hsieh HY, Hsieh $\mathrm{CH}$. Location of femoral fractures in patients with different weight classes in fall and motorcycle accidents. Jun 2018; 15(6):1082.

19. Alturki AA, Alaqeely KS, Almugren TS, Alzimami AS. Analysis of femoral fracture post motor vehicle accidents. 2019; 40(1):41-44.

20. Elsoe R, Ceccotti AA, Larsen P. Population-based epidemiology and incidence of distal femur fractures. Jan 2018; 42(1):191-196.

21. Mitchell SE, Keating JE, Robinson CM. The treatment of open femoral fractures with bone loss. Dec 2010; 92(12):1678-1684.

22. Ngunde PJ, Akongnwi ACN, Mefire CA, Puis F, Gounou E, Nkfusai NC, Nwarie UG, dkk. Prevalence and pattern of lower extremity injuries due to road traffic crashes in Fako Division, Cameroon. 2019; 32:53.

23. Mittal R, Banerjee S. Proximal femoral fractures: Principles of management and review of literature. Jun 2012; 3(1):15-23. 